\title{
Indicators of Sustainable Leadership for Secondary School Principals: Developing and Testing the Structural Relationship Model
}

\author{
Warada Paweenwat ${ }^{1}$, Phrakru Dhammapissamai ${ }^{1} \&$ Paisan Suwannoi ${ }^{2}$ \\ ${ }^{1}$ Faculty of Education, Mahamakut Buddhist University Isan Campus, Khon Khaen, Thailand \\ ${ }^{2}$ Human Resource Development Center, Khon Khaen University, Khon Khaen, Thailand \\ Correspondence: Prakru Sutheejariyawat, Program of Educational Administration Program, Faculty of \\ Education, Mahamakut Buddhist University, Northeastern Campus, Thailand. Tel: 668-3149-3809. E-mail: \\ sakorn2514@gmail.com
}

Received: July 21, 2018

Accepted: September 3, 2018

Online Published: January 30, 2019

doi: $10.5539 /$ ies.v12n2p36

URL: https://doi.org/10.5539/ies.v12n2p36

\begin{abstract}
The objectives of this study included to study the appropriateness of indicators for selection in the developed model, to examine the fitness of the developed model, and to verify the factor loading value of major components, sub-components, and indicators, respectively. Sample included 2,359 secondary school principals under the jurisdiction of the Office of the Basic Education Commission. Collecting data using a set of rating scale questionnaires were derived from 860 randomly selected proportional random sampling. Data were analyzed by using statistical program and AMOS program. The findings were corresponded to the following hypotheses: (a) The 62 indicators were suitable for the criteria as average equal to or higher than 3.00 and distribution coefficients equal to or less than $20 \%$ which were selected in the model, (b) The developed models were fitted with empirical data according to the value of relative Chi-square (CMIN/DF), root mean square error of approximation (RMSEA), goodness-of-fit index (GFI) adjusted goodness-fit index (AGFI), comparative fit index (CFI), and normed fit index (NFI) in accordance with the criteria from first and second order of confirmative factor analysis, and (c) the major components had factor loading ranged from 1.00 to 1.28 , which were higher than the criterion at 0.70 . The minor components had factor loading between 0.83 and 1.28 . The indicators had factor loading ranged from 0.88 to 1.16 , which are higher than the criterion as 0.30 , respectively.
\end{abstract}

Keywords: indicators, leadership, sustainable leadership, secondary school administrators

\section{Introduction}

\subsection{Research Problem}

Under the pattern of educational change in the current era of Thai education management and in the middle of the stream, the world is evolving named globalization, which is subject to competitive conditions to create an advantage, the commitment of the fast, violent and diverse society. It also affects the professional circle. In particular, education is the result of change the context and administrative structure of education management under the substance of the provisions of the educational law, called. "National Education Act 1999" aiming to provide quality education (Office of Educational Reform, 2002). The second decade of education reform is a must-see in the next ten years. Thai people in the future are good people, happy people, maintaining a sense of Thainess and knowing the circumstances of the world. The development of new teachers is through the production process. The training of teachers has been made to have the spirit and professional training. The new management focuses on decentralization to ensure the most flexible and independent school administration, along with the emphasis on good governance (Office of the Secretary of the Education Council, 2011). The importance of developing good leaders and leadership development can be seen because the leadership of education has a variety of academic views such as leadership style including behavioral leadership, situational leadership, change leadership, effective leadership, and team leadership for the 21 st century.

The key to success in quality management is education. Leadership is the ability to bring change and the ability to face challenges in new ways. To achieve the goals, it is important for the school administrators to get professional development as the school is the first institution to teach. Leadership is essential of a leader in all aspects of leadership in the rapidly changing world of change and extensive in terms of objects, society, environment and 
culture (Kriengsak, 2007, cited in Prayudhoo, 2005). It has been mentioned that good school administrators are effective when linked between successful schools and effective principals (Murphy, 1997, cited in Prayudhoo, 2005), which corresponds to Weber's (1989, cited in Siddhi \& Aareerat, 2010). Strong leadership of school administrators is an important feature of successful schools. The changing trends and the arousal are the components that characterized sustainable leadership for school administrators in society. From the synthesis of components which were characterized sustainable leadership from 19 sources including Fullan (2005), Hargreave and Fink (2006), Acutt (2008), Ceasar (2011), Lambert (2012), Nelson (2011), Faruk and Hoffmann (2012), Riedy (2012), Kanters (2013), Kross and Kitazume (2013), Courtice (2014), Simanskiene and Zuperkiene (2014), Lynch (2015), and Stanekzai (2016), respectively. In addition, Khonkarn (2004) found that 53 components of the theoretical framework characterized varied styles of the sustainable leadership. However, the main components used as a conceptual framework in the present study were four elements including clear vision, diversity, developmental leadership, and ethical leadership, respectively.

Thus, we are interested in developing models of structural relationships which are sustainable leadership indicators for secondary school administrators. We defined sub-variables and combined sub-variables with theoretical and fundamental theories. Then, we determined the weight of the sub-variables by analyzing empirical data according to Wiratchai (2002, cited in Khonkarn, 2004). This method would allow us to study related theories and other previous studies from a variety of sources. The sub-components and indicators leaded to structural modeling where we could examine the consistency of the developed model from related theories and other previous studies with empirical data. If the developed model was consistent with the empirical data, it showed that the new knowledge was appropriate to the context of Thai society. It then could be used as a reference for continuous research or for further development in the future. This study could be used as a guideline for planning development. We believed that this is a good way to monitor and evaluate the sustainability of high school administrators under the Office of the Basic Education Commission.

\subsection{Hypothesis}

Structural relationship model and other related indicators used in the present study were created and developed using the empirical definition, the sub-variables and the combining subsets with theoretical and fundamental research background. The way to determine the weight of the sub-variables was analyzed according to Wiratchai (2002, cited in Khonkarn, 2004). Because the present study was based on empiricism using a scientific approach, it was more reliable than pragmatic and theoretical studies. We had reviewed related theories and previous studies from a variety of sources. In addition, the research methodology was based on the globalization and leadership indicator for school administrators under the Office of the Basic Education Commission of the Environment (), previous study of the 21st century student identification for basic education: the development of a structural relationship model done by Tonark et al. (2016), and previous study of the performance indicator for employees of the revenue office. We then proposed the following hypothesis; (a) The indicators were appropriate for the structural relationship model which were the sustainable leadership indicator for secondary school administrators. According to Kan (2004), the mean was equal to or higher than 3.00 and had a distribution coefficient equal to or less than 20\%, (b) Developed model based on theoretical and previous studies were consistent with empirical data according to the criteria of Hair et al. (2010) as follows: (1) Relative chi-square (CMIN/DF) was 1-3 or less, (2) The mean square error of approximation (RMSEA) was less than 0.05, (3) Goodness-of-fit index (GFI), (4) Adjusted goodness-of-fit index (AGFI), and (5) Comparative fit index (CFI). The normalized fit index (NFI) was 0.90-1.00, and (c) Model had structural integrity. The loading factor of the main component was 0.70 (Farrell \& Rudd, 2009) and the component weight and indicator were equal to or higher than 0.70 (Tacq, 1997), respectively.

\subsection{Conceptual Framework}

Key components and sub-components of sustainable leadership for secondary school administrators were based on a review of the study of concepts, related theories, and previous studies. The conceptual framework for this study included:

(a) Clear vision consisted of imagination, planning, shared vision, and motivation or inspiration.

(b) Diversity consisted of integration, resource management, responsibility, and accountability

(c) Developing leaders consisted of keep promises, motivating, delegation, positive attitude.

(d) Ethical leadership consisted of respectfulness, honesty, moral courage.

The conceptual framework for research is shown in Figure 1. 


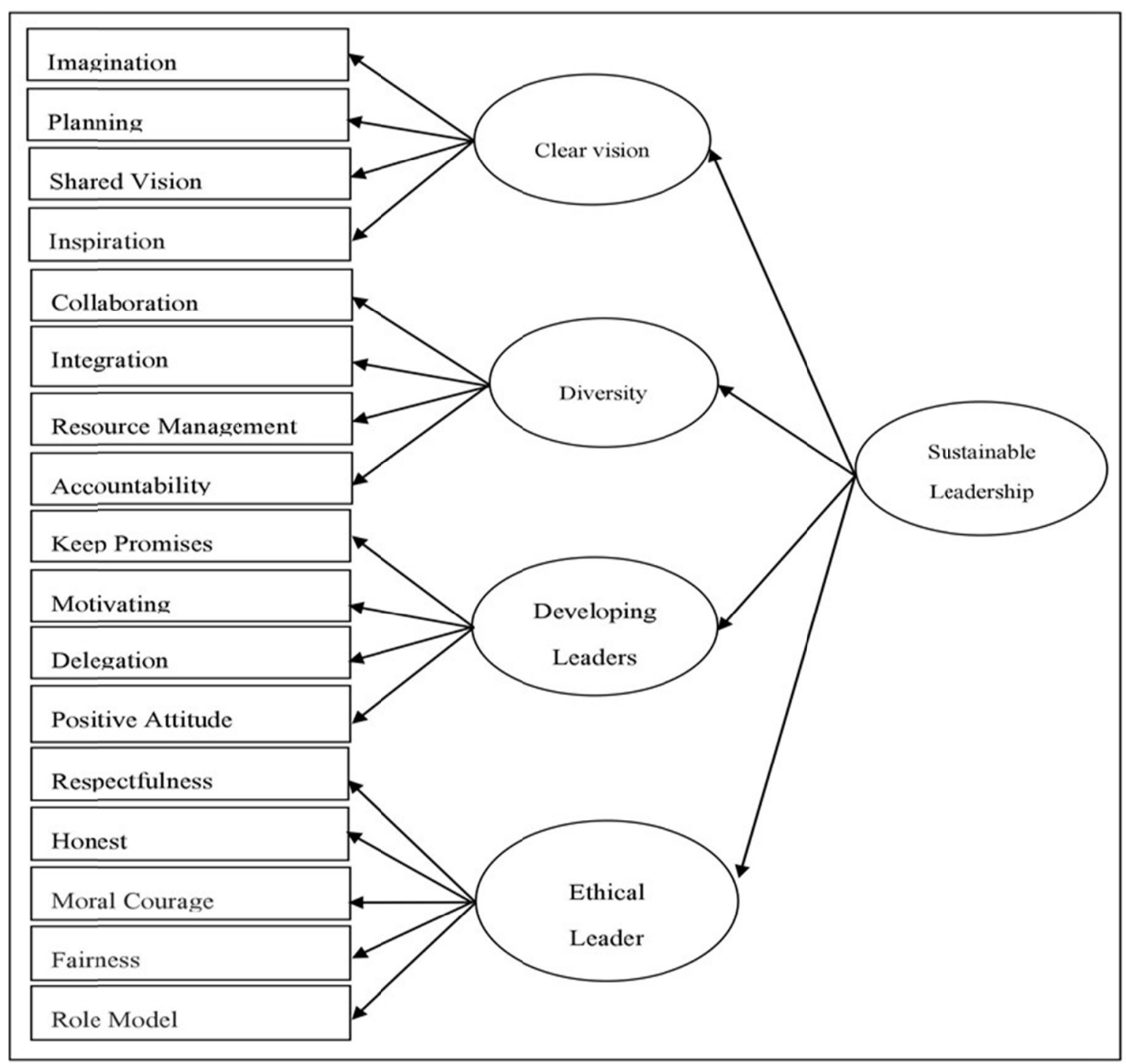

Figure 1. Theoretical model or hypothesis model: Conceptual framework for research

\subsection{Purpose of the Study}

The purpose of this study was (a) to examine the consistency of the model of structural relationships, sustainable leadership indicators for secondary school administrators, (b) to examine the consistency of the model of structural relationships, sustainable leadership indicators for secondary school administrators, and (c) to examine the key component, sub-component, and a sustainable leadership indicator for secondary school administrators.

\section{Method}

\subsection{Participants}

Population in this study was 2,381 educators in secondary school administration level of the information technology group), Office of the Basic Education Commission, academic year 2016. Sample size was determined by the ration of 20:1. The total of 43 parameters were used and totally 860 samples were included in the study.

\subsection{Materials}

The instrument used in this study was a questionnaire. It was divided into two phases incuding (a) questionnaire of respondents' status which was a checklist composing with gender, age, education and experience, and (b) sustainable leadership indicators. There were five levels of rating scale including highest, high, average, low, and lowest, respectively, classified by content. There were totally 62 questions. 


\subsection{Research Development}

We have developed the tools used in this study as follows: (a) studying all related theories and previous studies for analysis and define them as the main components, (b) studying all related theories and previous studies for analysis and define each sub-component, (c) studying all related theories and previous studies on the operational definition of each sub-components as an indication or primary basis for measuring each of the component, (d) creating a relationship to check the logical relationship between the main components, sub-component, and indicators, (e) at least five experts in educational administration examine the appropriateness of the questionnaire and the consistency of the questions with the indicator and the operational definition, (f) the questionnaire was revised and then used to try out with the sample of 30 secondary school administrators. The data were analyzed to find the alpha coefficient of reliability by using the Cronbach's method where the criteria were equal to or higher than 0.70 (Prasit et al., 2003). The results of the data analysis revealed that the questionnaire had the coefficient with 0.97. When identifying each component, it was clear that the composition had a clear vision of 0.92 . The diversity was 0.89 . Leadership development was 0.92 . The ethical leader was 0.89 , respectively.

\subsection{Data Collection}

In collected data, we used a proportional randomsampling method to obtain a sample of 860 from a population of 2,381. We then sent the official letter of the Faculty of Education, Mahamakut Buddhist University Northeastern Campus to the Office of Educational Service Area of the sample school in order to ask for permission to collect information from a sample school. We instructed all school to answer all the questionnaire and send the official letter of the Faculty of Education, Mahamakut Buddhist University Northeastern Campus. All questionnaires were mailed to the administrators of the post-secondary school and ask for help within 3 weeks by mail. If the questionnaire had not been returned within the specified period, we submitted a letter of cooperation to them in response to the questionnaire. The results showed that there were 747 questionnair returned, or 84.89 percent of the total. Considering the Kaiser-Meyer-Mikin (KMO) test for sampling adequate test of each model, it was found that the value ranged between $0.931-0.964$. The number of questionnaires and the number of samples were sufficient for the analysis of the confirmatory components.

\subsection{Data Analysis}

We analyzed all data by using the computer program to find the statistically significant as follows: (a) frequency and percentages indicated the baseline data of the sample, (b) average and distribution coefficients, (c) Pearson's product moment correlation coefficient (West et al., 2012), and Bartlett's statistic (Tobias \& Carlson, 2010) to determine the suitability of the variables, to examine for sampling adequate (Cerny \& Kaiser, 1977), Kaiser-Meyer-Olkin (KMO), and (d) first order confirmatory factor analysis to generate the scale components, and second order confirmatory factor analysis to develop the indicator (Bartholomew et al., 2011) by using statistical packages and AMOS programs.

\section{Results}

Indicators used in this study composed of 62 indicators which were appropriate according to the criteria in all models. The results included:

(1) Components of a clear vision which consisted of 4 components including (a) imagination, (b) planning, (c) shared vision, and (d) motivation. There were 14 indicators, average values ranged from 4.28 to 4.56 , and distribution coefficients ranged from 12.47 to 14.86 .

(2) Diverse composition which consisted of 4 sub-components including collaboration, integration, resource allocation, and responsibility, respectively. There were 13 indicators, average values ranged from 4.26 to 4.67 , and distribution coefficients were between 11.00 and 15.23.

(3) Components that created and developed a leader which consisted of 4 sub-components including (a) motivation, (b) job, (c) assignment, and (d) positive attitude, respectively. There were 16 indicators, average values ranged from 4.37 to 4.65 , and distribution coefficients were between 11.65 and 14.08 .

(4) Clements of ethical leadership which consisted of 5 sub-components including (a) respect for others, (b) integrity, (c) courage, and (d) morality, and be fair and a good example. There were 19 indicators, average values ranged from 4.61 to 4.76 , and distribution coefficients ranged from 9.59 to 12.37 .

The results of the conformance test of the structural relationship model of innovative leadership indicators for secondary school administrators showed that each measurement model was consistent with empirical data. The statistics for each model were as follows: (a) clear visual measurement model with CMIN DF $=2.750$, RMSEA $=$ $0.048, \mathrm{GFI}=0.967, \mathrm{AGFI}=0.945, \mathrm{CFI}=0.983$, and $\mathrm{NFI}=0.974,(\mathrm{~b})$ the measurement models of diversity were 
$\mathrm{CMIN} / \mathrm{DF}=2.541, \mathrm{RMSEA}=0.045, \mathrm{GFI}=0.976, \mathrm{AGFI}=0.952, \mathrm{CFI}=0.990$ and $\mathrm{NFI}=0.983,(\mathrm{c})$ the measurement model of building and developing leaders with $\mathrm{CMIN} / \mathrm{DF}=2.561$, RMSEA $=0.046, \mathrm{GFI}=0.959$, $\mathrm{AGFI}=0.944, \mathrm{CFI}=0.983$, and $\mathrm{NFI}=0.972$, (d) the measurement model of ethical leadership with $\mathrm{CMIN} / \mathrm{DF}=$ 2.521, $\mathrm{RMSEA}=0.045, \mathrm{GFI}=0.958, \mathrm{AGFI}=0.935, \mathrm{CFI}=0.985$ and $\mathrm{NFI}=0.975$. Based on the second confirmed component analysis, the measurement model of sustainable leadership with $\mathrm{CMIN} / \mathrm{DF}=2.458, \mathrm{RMSEA}=0.044$, GFI $=0.966$, AGFI $=0.942, \mathrm{CFI}=0.988$, and NFI $=0.989$ (Table 1$)$.

The results of the weighting of the components found that the main components, sub-components, and indicators had positive values with statistically significant at .01 level as follows: (a) the four main components of sustainable leadership (SUST) was 1.00 - 1.28, (b) all four components had a clear vision (VIS) ranging from 0.83 to 1.00 , (c) the four sub-components of DIV had a value from 1.00 to $1.18,(\mathrm{~d})$ the four sub-components of the creation and development of the leader (DEL) was from 1.00 to 1.28, (e) the five sub-components was ethical leadership (ETH) ranging from 0.91 to 1.00 . In addition, it was found that the factor loading of the 62 indicators was positive, ranging from 0.88 to 1.16 with statistically significant at .01 level. This indicated that structural relationships, sustainable leadership indicators for Secondary School Administrators, composed of four main components, 17 sub-components and 62 indicators, respectively. These can be used to measure innovative leadership indicators for secondary school administrators.

Table 1. First and second affirmative analysis results to examine the consistency of models

\begin{tabular}{lcccc}
\hline \multicolumn{3}{c}{ Element } & \multicolumn{3}{c}{ Matrix weight } & \multicolumn{1}{c}{ Predictive coeffieient } \\
\cline { 2 - 3 }$\left(\mathrm{R}^{2}\right)$
\end{tabular}




\section{Discussion}

Based on our findings, the 62 indicators averaged between 4.26 and 4.76, and the distribution coefficients ranged between 9.59 and 15.23, respectively, were the appropriate indicators each model. Because the mean was equal to or greater than 3.00 and the distribution coefficient was equal to or less than $20 \%$, it might be due to the creation and development of an indicator for this study. We studied all related theories and previous studies to develop an indicator by systematic analysis and synthesis of the main components, sub-components, and indicators. The theoretical frameworks and conceptual frameworks were based on theoretical and applied research. Based on the principle of constructing and developing the indicator, we used an empirical definition that determines the model of structural relationships. As shown by Othman and Rahman (2013) and according to the recommendations by Maladzhi et al. (2012), the good characteristics of the indicator should compose of meaning and interpretation, and content validity. Moreover, determining the value of the indicator does not result from the thinking of itself because it can be measured and compared with other factors as it is a basic unit for the theory. Verification of the quality of the indicator under a theoretical framework is also the impotant issue to be concerned. In our findings, the results of the 62 indicators were ascertained. Additionally, the mean and distribution coefficients were in line with our criteria in every model. Furthermore, it was found that the developed models were consistent with the empirical data. The first confirmed component analysis model was the VIS Measurement Model, the DIV Measurement Model, the DEL Model, and the Measurement Model of the Condition, and the Ethical Leadership Model (ETH), respectively. The first affirmative component was the Sustainable Leadership Measurement Model for Secondary School Administrators (SUST). Therefore, this study had led to the following two perspectives.

(a) Globalization is the age of distribution or dissemination of information. This includes exchanging educational information. Research and other information can be spread around the world. Exchanging experience and distribution of information from one to another is a part of the world (Davidovich, 2010). In addition, it may be due to the advancement of digital technology or the internet, which can make theories and research from one source spread to many more quickly and efficiently. People can access to the internet at anytime and anywhere. Also, there will be the online learning for everyone Maladzhi et al. (2012). In the 21st century, the center of the world was moving from west to east especially in Asia. There are many emerging trends in Asia (Kriengsak, 2007, cited in Prayudhoo, 2005). Therefore, it is possible that the principles and concepts of sustainable leadership presented by various scholars in this study were in the line with all previous studies (Fullan, 2005; Acutt; 2008; Ceasar; 2011; Faruk \& Hoffmann, 2012; Kanters, 2013; Courtice, 2014; Simanskiene \& Zuperkiene, 2014; Lynch, 2015; Stanekzai, 2016). Additionally, it has spread to Thai society and the educational society of Thailand from the age of globalization. The development of technology showed that sustainable leadership development also occurred with secondary school administrators. One has emerged from the external science into the informal society and was absorbed by the social mechanisms.

(b) In terms of empirical data, the sample used in the study was the group of secondary school administrators. They demonstrated the sustained leadership behaviors in the same direction as the related theories and previous studies used in this study. As Thailand trying to develop the country with the concept of Thailand 4.0, which is focused on the digital economy, knowledge-based economy, creative economy, the novelty that leads to business and competitiveness and sustainability are important factors Khonkarn (2004). Moreover, as it was evident from the education reform in the second decade (2009-2018), Thai people were committed for the lifelong learning way. There were three main goals including (a) to improve quality of education and learning of Thai people, (b) to increase educational opportunities to learn thoroughly and quality, and to promote the participation of all sectors of society in the administration and management of education, respectively. In addition, there were four frameworks for reform of education for the development of modern Thai people including (a) new teacher development, (b) new school quality development, (c) learning resources, and (d) developing new management quality, respectively (Office of Higher Education Policy and Planning, cited in Anand \& Saraswati, 2014).

In the case of model compatibility, it was found that the structural relationships model and sustainable leadership indicators for secondary school administrators consisted of 4 main components, 17 sub-components, and 62 indicators, respectively. These indicators can be used both academically and confidently. We can summarize in several perspectives including (a) to help in acquiring new knowledge that is appropriate to the context of Thai society. It can be used as a reference for further study, (b) to use for other types of study such as structural equation modeling, research and development, or participatory action research, (c) to enable the ability to reduce duplication of data. The organization can use it to track, review, and decide on the organization's operations. In addition, it can be applied to all levels whether it is a national organization or a sub-agency, (d) to use as a guideline for planning or establishing a benchmark for sustainable leadership for secondary school administrators to address the weaknesses in personnel development in a consistent manner, (e) to use as a monitoring tool for decision 
making and evaluation as well as the use of educational management. Moreover, this study can be used as a framework for the development of sustainable leadership for secondary school administrators (Figure 2).

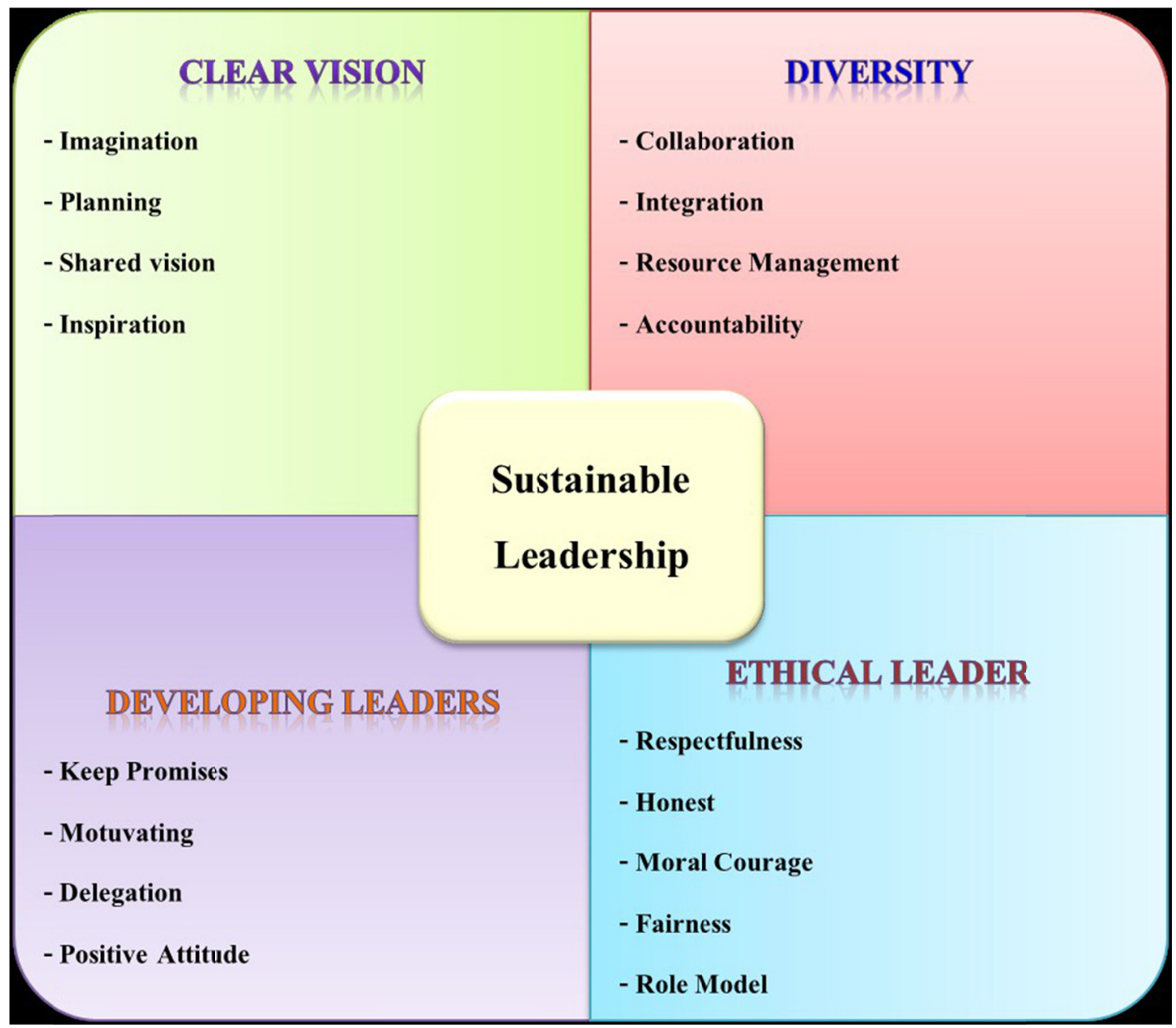

Figure 2. Conceptual framework for implementing the structured relationship model sustainable leadership indicator for secondary school administrators to utilize management

Based on our findings, several suggestions were listed as follows:

(a) Some suggestions should be taken place on the application of research results to the administration of education. As the models derived from the present study can be used to reduce data in an easy-to-use format, to reduce the duplication of data, the organization can use it to monitor, review and decide on the operations of the organization. In addition, it has features that can be used at all levels whether it is a national organization in subordinate units. The developed model in this study should be used as a guideline for planning, monitoring, evaluating or developing sustainable leadership for secondary school administrators as well at the main components, sub-components, and indicators, respectively.

(b) More studies should be done with the policy-oriented or practical suggestions such as guidelines for planning or establishing benchmarks for sustainable leadership for secondary school administrators in order to determine the strengths and weaknesses of development in the right direction. This will help to reduce the quality of education for the school under the Office of the Basic Education Commission, the County Office of Education, and the Office of Basic Education Commission, respectively. The findings in this study were useful for monitoring and evaluation purposes. In addition, it can be used as a control for the organization which is the process of regulating the work to meet the standards or goals of the organization. It is also the process by which individuals, groups, or organizations to determine what individuals, groups or organizations do to achieve the purpose of the organization, to ensure that members of the organization behave in a way that will achieve the standard or goal, focus on more desirable behavior and reduce unwanted behavior, respectively. 
More suggestions related to academic and administrative benefits are as follows:

(a) Further study should be done to develop the structural equation modeling to study the effect of this study on academic issues. Knowing the factors that affected to the effective leadership both internal and external factors as well as both direct and indirect influences, respectively.

(b) Research and development should be conducted using the models tested by this study as a guideline in order to get the training program. In addition, the personnel development should have the characteristics of sustainable leadership that will result in the quality of secondary education.

(c) The main components should be further studied along with sub-components and indicators by qualitative research methodology from the context of Thai society in order to obtain models derived from qualitative research compared with models derived from this quantitative study.

(d) A model of structural relationships of sustainable leadership indicators should be developed for secondary school administrators under the jurisdiction of the Office of Basic Education, vocational education as well as higher education.

(f) Further study should be conducted to model the structural relationships of sustainable leadership indicators for secondary school administrators by using the main components, sub-components, or indicator which were not used in the present study. This will be the opportunity for studying a structured relationship model of sustainable leadership indicators for secondary school administrators.

\section{Conclusion}

In this study, all data were analyzed by using statistical program and AMOS Program. Our findings were based on the provided research hypotheses including (a) the 62 indicators were suitable for the criteria as average equal to or higher than 3.00 and distribution coefficients equaled to or less than $20 \%$ which were selected in the model, (b) the developed models were fitted with empirical data by the value of relative Chi-square (CMIN/DF), root mean square error of approximation (RMSEA), goodness-of-fit index (GFI) adjusted goodness-o-fit index (AGFI), comparative fit index (CFI), and normed fit index (NFI), respectively, in accordance with the criteria from both first order and second order of confirmative factor analysis, and (c) the major components had factor loading ranged from 1.00 to 1.28 , which were higher than the criterion as 0.70 . The sub-components had factor loading between 0.83 to 1.28 , while the indicators had factor loading ranged from 0.88 to 1.16 which are higher than the criterion as 0.30 .

\section{References}

Acutt, N. (2008). The qualities of a sustainable leader. Retrieved from http://www.greenbiz.com/blog/2008/07/06/qualities-sustainable-leader

Anand, P., \& Saraswati, A. K. (2014). Innovative leadership: A paradigm in modern HR practices. Global Journal of Finance and Management, 6(6), 497-502.

Bartholomew, D., Knotts, M., \& Moustaki, I. (2011). Latent variable models and factor analysis: A unified approach (3rd ed.). West Sussex, UK: John Wiley \& Sons. https://doi.org/10.1002/9781119970583

Ceasar, N. (2011). Characterizing leadership for sustainable development. Retrieved from http://www.theguardian.com/sustainable-business/leadership-sustainable-development-characteristics

Cerny, C. A., \& Kaiser, H. F. (1977). A study of a measure of sampling adequacy for factor-analytic correlation matrices. Multivariate Behavioral Research, 12(1), 43-47. https://doi.org/10.1207/s15327906mbr1201_3

Courtice, D. P. (2014). Leadership for sustainability. Retrieved from https://www.cisl.cam.ac.uk/about/people/director

Davidovich, R. (2010). Beyond School Improvement: The Journey to Innovative Leadership. United States: Corwin Press. https://doi.org/10.4135/9781483350387

Faruk, A. \& Hoffmann, A. (2012). Five traits of sustainability leaders. Retrieved from http://www.bsr.org/en/our-insights/blog-view/five-traits-of-sustainability-leaders

Fullan, M. (2005). Leadership \& sustainability: System thinkers in action. Paper presented for Hot Seat. England: Urban Leadership Community.

Gold, R. Z. (1980). Introduction to bivariate and multivariable analysis. Illinois: Scott, Forman.

Hair, J. F., Black, W. C., Babin, B. J., \& Anderson, R. E. (2010). Multivariate data analysis (7th ed.). Upper Saddle River, NJ: Prentice Hall. 
Hargreave, A., \& Fink, D. (2006). Sustainable leadership. Retrieved from https://s3.amazonaws.com/academia.edu.documents/6473912/hargreaves.pdf?AWSAccessKeyId=AKIAIW OWYYGZ2Y53UL3A\&Expires $=1534780279 \&$ Signature $=\mathrm{i} 4 \mathrm{rytn} 5 \mathrm{~d} 8$ Y $8 \mathrm{e} 96 \mathrm{HjmlVrKqK} \% 2 \mathrm{FRFs} \% 3 \mathrm{D} \& \mathrm{resp}$ onse-content-disposition=inline $\% 3 \mathrm{~B} \% 20$ filename $\% 3 \mathrm{DS}$ stainable_leadership.pdf

Kanters, N. (2013). Sustainable leadership: Research on the development of a guideline for sustainable leadership. Retrieved from https://repository.uvh.nl/uvh/bitstream/handle/11439/130/Thesis\%20Sustainable\% 20leadership $\% 20$ Nora $\% 20$ Kanters.pdf? sequence $=1$

Kerlinger, F. N., \& Lee, H. B. (2000). Foundations of behavioral research (4th ed.). Holt, NY: Harcourt College Publishers.

Khonkarn, S. (2004). Development of indicators for public higher education institutions (Doctor of Education, Faculty of Graduate Studies, Srinakharinwirot University).

Kross, K., \& Kitazume, K. (2013). Five traits essential for sustainability leadership. Retrieved from http://www.triplepundit.com/2013/09/5-traits-essential-sustainability-leadership/

Lambert, S. (2012). The perception and implementation of sustainable Leadership strategies in further education colleges. Journal of Leadership Education, 11(2),102-120. https://doi.org/10.12806/V11/I2/RF6

Lynch, M. (2015). The seven principles of sustainable leadership. Retrieved from http:/www.theedadvocate.org/the-seven-principles-of-sustainable-leadership/

Maladzhi, W. R., Yan, B., \& Makinde, D. (2012). The impact of innovative leadership on organizational culture within South African small and medium enterprises in Western Cape, South Africa. African Journal of Business Management, 6(39), 10438-10444. https://doi.org/10.5897/AJBM12.749

Meador, K. L. (2013). School of law. Retrieved from https://www.law.ua.edu /alumni/alumni-news/november-2013-meador-lecture/

Nelson, J. (2011). What is corporate sustainability leadership? Retrieved from https://www.cisl.cam.ac.uk/publications/archive-publications/what-is-corporate-sustainability-leadership

Othman, A., \& Rahman, H. A. (2013). Innovative Leadership: Learning from Change Management among Malaysian Secondary School Principals. World Applied Sciences Journal, 23(2), 167-177.

Riedy, C. (2012). The characteristics of sustainability leaders. Retrieved from http://chrisriedy.me/2012/03/20/the-characteristics-of-sustainability-leaders/

Sheninger, E. (2011). Digital leadership: Changing paradigms for changing time. New York: A Joint Publication

Simanskiene, L., \& Župerkiene, E. (2014). Sustainable leadership: the new challenge for organizations. Forum Scientiae Oeconomia, 2(1), 81-93.

Stanekzai, A. I. (2016). The characteristic of Leadership-Seven important traits. Retrieved from https:/www.linkedin.com/pulse/characteristic-leadership-7-important-traits-stanekzai

Tacq, J. (1997). Multivariate Analysis Techniques in Social Science Research: From problem to analysis. London: SAGE Publications Ltd.

Tobias, S., \& Carlson, J. E. (2010). Brief report: Bartlett's test of sphericity and chance findings in factor analysis. Journal of Multivariate Behavioral Research, 4(3), 17-24.

Tonark, K., Chamchoi, S., \& Kornphuang, A. (2016). An analysis of innovative leadership elements for basic school administrators. Journal of Naresuan University, 16(4), 131-139.

Visser, W. (2013). The seven habits of effective sustainability leaders. Retrieved from http://www.waynevisser.com/articles/7-habits-sustainability-leaders

West, S. G., Taylor, A. B., \& Wu, W. (2012). Model fit and model selection in structural equation modeling. In R. H. Hoyle (Ed.), Handbook of structural equation modeling. New York: Guilford.

\section{Copyrights}

Copyright for this article is retained by the author(s), with first publication rights granted to the journal.

This is an open-access article distributed under the terms and conditions of the Creative Commons Attribution license (http://creativecommons.org/licenses/by/4.0/). 